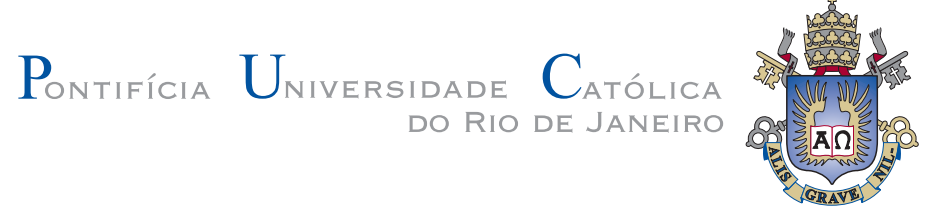

Rosane Vasconcelos Zanotti

O cotidiano pelas lentes do celular

Tese de Doutorado

Tese apresentada como requisito parcial para obtenção do título de Doutor em Design pelo Programa de Pósgraduação em Design do Departamento de Artes \& Design da PUC-Rio.

Orientadora: Profa. Vera Lúcia Moreira dos Santos Nojima 


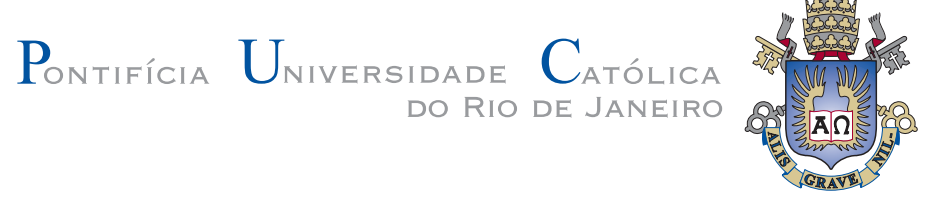

Rosane Vasconcelos Zanotti

\section{O cotidiano pelas lentes do celular}

Tese apresentada como requisito parcial para obtenção do título de Doutor em Design ao Programa de Pós-graduação em Design do Departamento de Artes \& Design da PUC-Rio. Aprovada pela comissão examinadora abaixo assinada.

Profa. Vera Lúcia M. dos Santos Nojima Orientadora Departamento de Artes \& Design - PUC-Rio

Profa. Maria Manuela Rupp Quaresma Departamento de Artes \& Design - PUC-Rio

Profa. Jackeline Lima Farbiarz Departamento de Artes \& Design - PUC-Rio

Profa. Rita Maria de Souza Couto Departamento de Artes \& Design - PUC-Rio

Prof. José Antonio Martinuzzo Universidade Federal do Espírito Santo - UFES

Prof. José Maria Gonçalves da Silva Ribeiro Universidade Aberta - Portugal - UAB

Profa. Denise Berruezo Portinari Coordenadora Setorial de Pós-Graduação e Pesquisa do Centro de Teologia e Ciências Humanas - PUC-Rio 
Todos os direitos reservados. É proibida a reprodução total ou parcial do trabalho sem autorização da universidade, da autora e da orientadora.

\section{Rosane Vasconcelos Zanotti}

Graduada em Comunicação Social/Publicidade e Propaganda pela Universidade Federal do Espírito Santo (UFES) em 1994. Mestre em Design pela Pontifícia Universidade Católica do Rio de Janeiro (PUC-Rio) em 2005. Professora do Departamento de Comunicação Social da Universidade Federal do Espírito Santo (UFES) desde 2005, investigadora do Laboratório de Comunicação e Cotidiano/UFES e do Laboratório de Antropologia Visual/Centro de Estudos das Migrações e das Relações Interculturais da Universidade Aberta (CEMRI/UAB Portugal) desde 2011.

Ficha Catalográfica

Zanotti, Rosane Vasconcelos

O cotidiano pelas lentes do celular / Rosane Vasconcelos Zanotti; orientadora: Vera Lúcia Moreira dos Santos Nojima - 2013.

185 f. : il.(color.) ; $30 \mathrm{~cm}$

Tese (doutorado) - Pontifícia Universidade Católica do Rio de Janeiro, Departamento de Artes e Design, 2013.

Inclui bibliografia

1. Artes e Design - Teses. 2. Imagens. 3. Tecnologia. 4. Fotografia. 5. Cotidiano. 6. Comunicação. I. Nojima, Vera Lúcia Moreira dos Santos. II. Pontifícia Universidade Católica do Rio de Janeiro. Departamento de Artes \& Design. III. Título. 
Para meus pais, Beatriz e Wilson. 


\section{Agradecimentos}

Sou imensamente grata: à professora orientadora, Vera Nojima, que novamente me acolheu e me conduziu nessa caminhada de quatro anos com o carinho, a dedicação e os ensinamentos imprescindíveis para a construção desse aprendizado; à CAPES, à PUC-Rio e à UFES pelo financiamento desse estudo; aos professores que, gentilmente, aceitaram compor a banca de defesa desta tese; aos professores da PUC-Rio, em especial aos do Departamento de Artes \& Design e aos funcionários dessa instituição; aos meus colegas do Departamento de Comunicação Social da UFES e aos funcionários desse Departamento, em especial à Tia Hélia; à PRPPG/UFES, em especial ao Carlos Alberto Andrade; aos funcionários do NPD/UFES, em especial ao Igor Magri Vale; aos meus colegas do CEMRI e do Laboratório de Antropologia Visual da Universidade Aberta, em especial ao Casimiro Alberto Moreira Pinto.

Ao Prof. Dr. José da Silva Ribeiro, que me recebeu não só no Laboratório de Antropologia Visual mas em seu País, pela acolhida, ensinamentos acadêmicos e de vida, caminhadas, jantares, seminários, congressos e amizade preciosa. Ao meu anjo da guarda, o amigo-irmão que a vida me deu de presente, José Antonio Martinuzzo, agradeço pelo prazer da convivência e pelo privilégio de aprender com o profissional competente e o ser humano raro. Ao meu amor, Renan, por ser um companheiro tão valioso, por participar intensamente desse doutorado, tanto como parceiro de viagem quanto de empreitada, pelo envolvimento na pesquisa do inicio ao fim e pelos cuidados comigo. À minha equipe multidisciplinar: Adélia, Alê, Douglas, Dri, Gisela, Mariane, Nath, Susane, Walter e Yugo, pelo suporte operacional e emocional que só as relações de amor conseguem produzir. Aos meus pais, pela educação preciosa que me leva tão longe e à minha família, por termos construído uma vida tão feliz. 


\section{Resumo}

Zanotti, Rosane Vasconcelos; Nojima, Vera Lúcia Moreira dos Santos (Orientadora). O cotidiano pelas lentes do celular. Rio de Janeiro, 2013. 185p. Tese de Doutorado - Departamento de Artes \& Design, Pontifícia Universidade Católica do Rio de Janeiro.

O estudo discute os impactos gerados pelo uso de um dispositivo comunicacional nas práticas de registros fotográficos. Investiga a fotografia amadora produzida a partir da integração entre câmera e aparelho de telefonia celular, debruçando o olhar sobre uma forma peculiar de narrativa do cotidiano, fundada na produção e difusão de imagens via tal artefato híbrido. A nosso ver, o desenvolvimento da comunicação em rede e a cultura da internet combinada com o telefone celular com câmera, interferem na experiência dos sujeitos com a fotografia, tanto na captura quanto na partilha, contribuindo para a ebulição de uma narrativa imagética do cotidiano. Participaram da pesquisa 347 brasileiros com idades entre 16 e 66 anos e 28 portugueses com idades entre 24 e 66 anos, de ambos os sexos. Os resultados indicam que a relação entre fotografia e memória divide espaço com as imagens capturadas com fins utilitários, comunicativos e de vínculo social. Os fotógrafos do cotidiano fazem uso do celular com câmera enquanto dispositivo ajustado ao seu desejo e exercício de bricolagem, à (re) invenção diária dos registros da vida. Dessa forma, observamos como a câmera incorporada ao telefone celular trouxe não só novos usos ao aparelho, mas também à fotografia. As repercussões desta investigação colaboram com a avaliação dos processos hoje envolvidos no ato fotográfico, absorvido pelas relações de comunicação e trocas sociais alargadas pelas ferramentas tecnológicas digitais.

\section{Palavras-chave}

Imagens; tecnologia; fotografia; cotidiano; comunicação. 


\section{Abstract}

Zanotti, Rosane Vasconcelos; Nojima, Vera Lúcia Moreira dos Santos (Advisor). Everyday life images by mobile phone. Rio de Janeiro, 2013. 185p. DSc. Thesis - Departamento de Artes \& Design, Pontifícia Universidade Católica do Rio de Janeiro.

This work argues about the impacts generated by the use of a communication device in photo register's practices. Investigate the amateur photo produced from the harmony found between a camera and a cell phone, launching a look over a peculiar way to see everyday life, built over the production and diffusion of images through such hybrid device. According to our understand, the development of net communication and the internet culture combined to the cell phone equipped with a cam, interferes in the experience subjects may have with photography, as much in capture as in sharing, contributing to a big imagery narrative of everyday life. Participated in this study, 347 Brazilians aged between 16 and 66 years and 28 Portuguese aged between 24 and 66 years, both genders. The results indicate the relation between photography and memory occupying the same space of images captured with utilitarian, communicational and social goals. The everyday life photographers uses cell phones with cameras as a device adjusted to their desire of bricolage, to the daily creation of the registers of life. We observed how the cam in cell phone brought not only new uses to the device but for photography as well. The repercussions of this investigation collaborates with the evaluation of nowadays photography's process, absorbed by the communication relations and social exchanges widened by digital technological tools, offering elements so we can understand how technology negotiates today with the cultural practices.

\section{Keywords}

Images; technology; photography; everyday life; communication. 


\section{Resumen}

Zanotti, Rosane Vasconcelos; Nojima, Vera Lúcia Moreira dos Santos (Tutor). La vida cotidiana a través de las lentes del celular. Rio de Janeiro, 2013. 185p. Tesis Doctoral - Departamento de Artes \& Design, Pontifícia Universidade Católica do Rio de Janeiro.

El estudio discute los impactos generados por el uso de un dispositivo de comunicación en la practica de registros fotográficos, investiga la fotografía aficionada producida a partir de la integración entre una camera y el aparato de telefonía celular, sobreponiendo su visión de una forma muy peculiar de la narrativa del cotidiano, fundada en la producción y difusión de imágenes a través de este artefacto híbrido. Para nosotros, el desenvolvimiento de la comunicación en red y la cultura del internet combinada con el teléfono celular con camera interfieren en la experiencia de las personas con la fotografía tanto en la captura cuanto en el compartir, contribuyendo a la ebullición de una narrativa de imágenes del cotidiano. Participaron en la encuesta 347 brasileños con edades entre los 16 y los 66 años, y 28 portugueses con edades entre 24 y 66 años, de ambos sexos. Los resultados nos indican que la relación entre fotografía y memoria divide el espacio con las imágenes sacadas para medios útiles, comunicativos y de vínculo social. Los fotógrafos del cotidiano hacen uso de los celulares con camera cómo dispositivo configurado para su deseo, cómo un ejercicio de artesanía, y también cómo la reinvención diaria de sus registros de vida. De esa forma, observamos cómo la camera agregada al teléfono celular nos ha traído no solo nuevos usos para el aparato cómo también para la fotografía. Las repercusiones de esa investigación colaboran con la evaluación de los procesos hoy involucrados en el ato fotográfico, absorbido por las relaciones de comunicación y los intercambios sociales aumentados por herramientas tecnológicas digitales.

\section{Palabras-llave}

Imágenes; tecnología; fotografía; cotidiano; comunicación. 


\section{Zusammenfassung}

Zanotti, Rosane Vasconcelos; Nojima, Vera Lúcia Moreira dos Santos (Tutor). Der Alltag durch der Handy-Linsen. Rio de Janeiro, 2013. 185p. Doktorarbeit - Departamento de Artes \& Design, Pontifícia Universidade Católica do Rio de Janeiro.

Dieser Arbeit präsentiert die Auswirkungen erzeug durch die Verwendung von einer Kommunikationsvorrichtung in die Praktiken der fotografischen Aufzeichnungen, untersucht die Amateurfotografie aus der Integration zwischen Kamera und Handy produziert, angelehnt an den Sicht einer eigentümlichen narrative des Alltags, basiert auf die Produktion und Verbreitung von den Bilder, die über dieser Hybrid-Artefakt gemacht sind. Aus unserer Sicht die Entwicklung von Netzwerk-Kommunikation und die Kultur des Internets plus der KameraHandys mit der Erfahrung der Fotografie-Subjekts interferieren, sowohl beim Fotografieren als beim Aktien, die zu der Siedepunkt einer narrative Bildsprache des täglichen Lebens beitragen. So führten wir eine Studie wo 347 Brasilianer, im Alter von 16 bis 66 Jahren alt und 28 Portugieser zwischen 24 und 66 Jahren alt beide Geschlechter - teilgenommen haben. Die Ergebnisse zeigen, dass die Beziehung zwischen Fotografie und Erinnerung teilt sich den Platz mit Bildmaterial für nützliche Zwecke, kommunikative und soziale Bindung. Den Alltag-Fotografen nutzen der Kamera-Handy wie ein Gerät, der zu Ihrem Wunsch und Ausübung der Handwerk, die (Wieder-) Erfindung von Alltag Datensätzen angepasst wird. So sehen wir, wie die Kamera in das Handy gebaut, neue Anwendungen nicht nur auf das Gerät gebracht hat, sondern auch zur Fotografie. Die Auswirkungen dieser Forschung hängt mit der Auswertung der Prozesse heute beteiligt in der fotografischen Akt zusammen, absorbiert durch die Beziehungen der Kommunikation und sozialen Austausch, die von digitalen Technologie-Werkzeuge erweitert sind. Und so bietet es uns Elemente, sodass wir verstehen können, wie die Technologie heute mit kulturellen Praktiken verhandelt.

\section{Stichwort}

Bilder; technologie; fotografie; alltag; kommunikation. 


\section{Sumário}

$\begin{array}{ll}\text { Agradecimentos } & 5\end{array}$

$\begin{array}{ll}\text { Lista de figuras } & 13\end{array}$

1 Introdução 16

1.1. Justificativa 17

1.2. Objetivos e percurso 20

2 A imagem no cotidiano 25

2.1. O cotidiano 25

2.2. Cotidiano digital 27

2.3. Ver e ser visto 33

$\begin{array}{ll}\text { 2.4. Transmitir-se } & 37\end{array}$

30 cotidiano na imagem 42

3.1. Percurso da fotografia cotidiana 42

3.2. Fotografia e memória 46

3.3. Decurso digital 49

3.4. Artefatos de foto e fala 51

3.4.1. Objeto de desejo 54

40 percurso às novas práticas $\quad 58$

4.1. Escolha dos procedimentos 58

4.2. Escolha dos participantes $\quad 59$

4.3. Procedimento para a coleta de informações 62

4.4. Tratamento dos dados $\quad 69$

4.5. Descrição da amostra 70

4.5.1. Grupos geracionais a partir da idade $\quad 71$

4.5.2. Grupos geracionais e grau de escolaridade 76

4.5.3. Grupos geracionais e atividade profissional 78 
$5 \mathrm{~A}$ prática das imagens

5.1. O ato fotográfico

5.2. Resultados: respondentes brasileiros 83

5.2.1. Que aparelhos digitais você usa para fotografar?

5.2.2. Qual dos aparelhos marcados acima você utiliza com mais frequência?

5.2.3. O que você mais utiliza para fazer fotos de...?

5.2.4. Quando fotografa com o celular, o que faz com as fotos? 106

5.2.5. Quando você publica na internet as fotos que estão no aparelho, onde faz?

5.2.6. Antes de publicar as fotos na internet você faz alterações com softwares de manipulação?

5.2.7. O que você fotografou?

5.2.8. Quando/há quanto tempo? 122

5.2.9. Por quê? 124

5.2.10. O que você fez com essa foto? 125

5.2.11. Caso tenha publicado na internet, onde? 127

5.2.12. Você também utiliza a função vídeo do celular? 129

5.3. Resultados: respondentes portugueses 134

5.3.1. Que aparelhos digitais você usa para fotografar? 135

5.3.2. Qual dos aparelhos marcados acima você utiliza com mais frequência? 136

5.3.3. O que você mais utiliza para fazer fotos de...? 136

5.3.4. Quando fotografa com o celular, o que faz com as fotos? 141

5.3.5. Quando você publica na internet as fotos que estão no aparelho, onde faz?

5.3.6. Antes de publicar as fotos na internet você faz alterações com softwares de manipulação?

5.3.7. O que você fotografou? 145

5.3.8. Quando/há quanto tempo? 146

5.3.9. Por quê? 
5.3.10. O que você fez com essa foto? 148

5.3.11. Caso tenha publicado na internet, onde? 149

5.3.12. Você também utiliza a função vídeo do celular? 150

5.4. Considerações sobre a prática das imagens 153

6 O cotidiano pelas lentes do celular - à guisa de conclusão 158

7 Referências bibliográficas 168

8 Anexo 175

8.1. Brasileiros com até 23 anos de idade: temas da última foto 175

8.2. Brasileiros com idade entre 24 e 35 anos: temas da última foto 177

8.3. Brasileiros com idade entre 36 e 47 anos: temas da última foto 182

8.4. Brasileiros com idade entre 48 e 66 anos: temas da última foto 184

8.5. Portugueses com idade entre 24 e 35 anos: temas da última foto 185

8.6. Portugueses com idade entre 36 e 47 anos: temas da última foto 185

8.7. Portugueses com idade entre 48 e 66 anos: temas da última foto 185 


\section{Lista de figuras}

Figura 1. Comunidade sobre celulares com câmera no Orkut 59

Figura 2. Twitter: perfis que distribuíram a pesquisa 61

Figura 3. Questionário utilizado para coleta de dados 65

Gráfico 1. Perfil dos respondentes brasileiros, por faixa etária $\quad 76$

Gráfico 2. Perfil dos respondentes portugueses, por faixa etária $\quad 76$

Gráfico 3. Perfil dos respondentes brasileiros, por faixa etária e grau de escolaridade $\quad 77$

Gráfico 4. Perfil dos respondentes portugueses, por faixa etária e grau de escolaridade $\quad 77$

Gráfico 5. Perfil dos respondentes brasileiros, por faixa etária e profissão

Gráfico 6. Perfil dos respondentes portugueses, por faixa etária e profissão $\quad 79$

Gráfico 7. Perfil dos respondentes brasileiros, por faixa etária e sexo $\quad 80$

Gráfico 8. Perfil dos respondentes portugueses, por faixa etária e sexo 80

Gráfico 9. Onde vivem os respondentes brasileiros 82

Gráfico 10. Aparelhos utilizados pelos brasileiros, por faixa etária $\quad 84$

Gráfico 11. Aparelhos utilizados por brasileiros, por faixa etária e grau de escolaridade $\quad 86$

Gráfico 12. Aparelhos utilizados por brasileiros, por faixa etária e profissão 88

Gráfico 13. Aparelhos utilizados por brasileiros, por faixa etária e sexo 91

Gráfico 14. Aparelho mais utilizado pelos brasileiros, por faixa etária 93

Gráfico 15. Aparelho mais utilizado por brasileiros, por faixa etária e grau de escolaridade $\quad 95$

Gráfico 16. Aparelho mais utilizado por brasileiros, por faixa etária e profissão

Gráfico 17. Aparelho mais utilizado por brasileiros, por faixa etária e sexo 
Gráfico 18. brasileiros com até 23 anos - associação entre aparelhos e temas

Gráfico 19. brasileiros com idade entre 24 e 35 anos - associação entre aparelhos e temas

Gráfico 20. brasileiros com idade entre 36 e 47 anos - associação entre aparelhos e temas

Gráfico 21. brasileiros com idade entre 48 e 66 anos - associação entre aparelhos e temas

Gráfico 22. brasileiros, por faixa de idade - associação entre telefones celulares e temas 105

Gráfico 23. brasileiros por faixa etária - o que fazem com as fotos 107

Gráfico 24. brasileiros por faixa etária - onde publicam as fotos

Gráfico 25. brasileiros - todos os grupos etários - sobre alterações feitas nas fotografias

Gráfico 26. brasileiros por faixa etária - último tema fotografado

Gráfico 27. brasileiros - quando fizeram a última fotografia com o celular

Gráfico 36. brasileiros por faixa etária - motivações para fotografar 124 Gráfico 37. brasileiros por faixa etária - destinação da fotografia 125 Gráfico 38. brasileiros por faixa etária - onde foi publicada a foto Gráfico 39. brasileiros - todos os grupos etários - o uso da função vídeo

Gráfico 40. brasileiros por faixa etária - destinação dos vídeos

Gráfico 41. brasileiros por faixa etária - onde publicam os vídeos

Gráfico 42. Aparelhos utilizados pelos respondentes portugueses, por faixa etária

Gráfico 43. Aparelho mais utilizado pelos respondentes portugueses, por faixa etária

Gráfico 44. portugueses com idade entre 24 e 35 anos - associação entre aparelhos e temas

Gráfico 45. portugueses com idade entre 36 e 47 anos - associação entre aparelhos e temas

Gráfico 46. portugueses com idade entre 48 e 66 anos - associação entre aparelhos e temas 
Gráfico 47. portugueses, por faixa de idade - associação entre telefones celulares e temas

Gráfico 48. portugueses por faixa etária - o que fazem com as fotos 141

Gráfico 49. portugueses por faixa etária - onde publicam as fotos

Gráfico 50. portugueses - todos os grupos etários - sobre alterações nas fotos

Gráfico 51. portugueses dos três grupos etários - último tema fotografado

Gráfico 52. portugueses por faixa etária - quando fotografaram pela última vez com o celular

Gráfico 53. portugueses por faixa etária - motivações para fotografar 147

Gráfico 54. portugueses por faixa etária - destinação da fotografia 148

Gráfico 55. portugueses por grupo etário - onde foi publicada a foto 149

Gráfico 56. portugueses - todos os grupos etários - o uso da

Gráfico 57. portugueses por faixa etária - destinação dos vídeos

Gráfico 58. portugueses por faixa etária - onde publicam os vídeos 